\title{
Bladder Alveolar Rhabdomyosarcoma
}

National Cancer Institute

\section{Source}

National Cancer Institute. Bladder Alveolar Rhabdomyosarcoma. NCI Thesaurus. Code C159669.

An alveolar rhabdomyosarcoma arising from the bladder. It is the most common type of rhabdomyosarcoma of the bladder affecting older children and adolescents. 